\title{
USO DE OZÔNIO GASOSO NA SANITIZAÇÃO DE CÂMARAS FRIGORÍFICAS
}

\author{
Use of gaseous ozone for sanitation cold room storage \\ Daniel Augusto Cavalcante ${ }^{1}$, Bruno Ricardo de Castro Leite Júnior ${ }^{2 *}$, \\ Alline Artigiani Lima Tribst ${ }^{2}$, Marcelo Cristianini ${ }^{2}$
}

\begin{abstract}
RESUMO
Este trabalho avaliou o uso do ozônio gasoso para sanitização de câmaras frias utilizadas para a estocagem de queijo minas frescal por 120 dias. A qualidade microbiológica do ar, das paredes e portas da câmara foram amostradas por 60 dias com e sem aplicação de ozônio a $0,03 \mathrm{mg} . \mathrm{L}^{-1}$. Foram utilizadas as técnicas de sedimentação para avaliação do ar (microrganismos aeróbios mesófilos e bolores e fungos filamentosos) e de esfregaço de superfície para avaliação das superfícies internas da câmara (microrganismos aeróbios mesófilos). Observou-se uma redução de microrganismos aeróbios mesófilos e bolores e fungos filamentosos de 0,81 e 1,01 ciclos logaritmos, respectivamente, no ar ambiente da câmara fria após a aplicação do gás ozônio. Além disso, a aplicação do sanitizante proporcionou reduções decimais estatisticamente significativas $(\mathrm{p}<0,05)$ para as contagens de aeróbios mesófilos nas paredes e porta da câmara, sendo, entretanto, sempre inferior a 0,5 reduções decimais. Assim, a utilização do gás ozônio melhorou a qualidade microbiológica do ar e das superfícies interna da câmara fria. Isto sugere o ozônio como um método alternativo para desinfecção de ambientes.
\end{abstract}

Palavras-chave: local de estocagem; gás ozônio; qualidade microbiológica do ar.

\begin{abstract}
This work evaluated the ozone application for sanitation of a cold room used to store Minas Frescal cheese during 120 days. The microbiological quality of the air, the

1 Fazenda da Aeronáutica de Pirassununga, I Comando da Aeronáutica, Pirassununga, SP, Brasil.

2 Universidade Estadual de Campinas (UNICAMP), Departamento de Tecnologia de Alimentos, Faculdade de Engenharia de Alimentos, Rua Monteiro Lobato, 80, Cidade Universitária "Zeferino Vaz", s/n, 13083-862, Campinas, SP, Brasil. E-mail: brunorclj@gmail.com

* Autor para correspondência.
\end{abstract}

Recebido / Received: 27/01/2014

Aprovado / Approved: 03/03/2014 
room walls and the room door were evaluated during 60 days with and with no addition of ozone at $0,03 \mathrm{mg}$.L-1. The air sedimentation technique was applied for the evaluation of the air quality (aerobic mesophilic microorganisms and yeasts and moulds) and the swab technique was used for the evaluation of internal surface counts of aerobic mesophilic microorganisms. Reductions of 0.81 and $1.01 \mathrm{log}$ cycles in the room air were caused by air ozonation. Additionally, significant decimal reductions around $0.50 \mathrm{log}$ were observed in the walls and door swabs of the cold room. Therefore, ozone gas has improved microbiological quality of the surfaces and the air of cold room. This suggests ozone as an alternative method for disinfection of rooms.

Keywords: storage rooms; ozone gas; air microbiological quality.

\section{INTRODUÇÃO}

Agarantia de um produto seguro vai além de um processamento bem controlado, sendo dependente da qualidade da matéria prima até a chegada do alimento à mesa do consumidor. Para alimentos refrigerados, a estocagem em câmara fria é uma etapa importante, entretanto, a limpeza e a sanitização das câmaras frigoríficas é negligenciada por grande parte das indústrias de alimentos (SALVADOR et al., 2006).

Os microrganismos presentes no ambiente de processamento e de estocagem de alimentos podem levar à contaminação do produto acabado (OLIVEIRA et al., 2011). As fontes de contaminação do meio ambiente incluem alimentos, manipuladores, animais, insetos, além de utensílios e componentes estruturais como portas, paredes e teto de armazéns e câmaras frigoríficas. $\mathrm{O}$ ar do ambiente, as embalagens primárias, as mãos dos operadores e os equipamentos constituem pontos importantes que devem ser considerados nas Boas Práticas de Fabricação, de forma a não representarem risco de contaminação para o produto (OTHMANE et al., 2011).

O queijo Minas Frescal deve ser embalado e ficar acondicionado em temperaturas não superiores a $8^{\circ} \mathrm{C}$, conforme Resolução $n^{\circ} 145$ do MAPA (BRASIL, 1996). Esses procedimentos (embalagem e temperatura de armazenamento) são importantes para garantir a vida de prateleira do alimento devido aos fatores intrínsecos como atividade de água, pH e composição nutricional.

Assim, a qualidade do ar das câmaras frias onde os queijos são armazenados até o seu transporte para os locais de comercialização é de grande importância, uma vez que é comum encontrar microrganismos patogênicos e deterioradores. Esses podem prejudicar a saúde de consumidores, bem como ocasionar prejuízos consideráveis para as indústrias, em virtude da diminuição da vida útil de seus produtos.

O ozônio é um forte agente antimicrobiano com alta reatividade e decomposição espontânea em produtos não tóxicos. Pode ser aplicado em alimentos nas formas líquida e gasosa (TIWARI et al., 2008; TIWARI et al., 2010). O ozônio molecular ou seus produtos de decomposição inativam microrganismos rapidamente, pela sua reação com elementos vitais da célula, como enzimas intracelulares, ácidos nucléicos e membranas celulares (GUZEL-SEYDIM et al., 2004). O ozônio é adequado para descontaminar produtos alimentícios, equipamentos, ambientes, superfícies que entram em contato com alimentos, tratar água e efluentes, entre outros (KIM et al., 1999; KHADRE; YOUSEF, 2001; KHADRE et al., 2001; DHILLON et al., 2009).

Segundo Veiga (2003), o ozônio pode ser utilizado na forma gasosa em câmaras frigoríficas, silos e depósitos de alimentos, com a finalidade de proteger e conservar pro- 
dutos acabados e matérias primas. A aplicação direta de gás ozônio em depósitos mantém o ambiente com reduzida carga microbiana, mesmo quando há altos índices de calor e umidade, o que assegura maior tempo de armazenamento e manutenção da qualidade dos alimentos.

Desta forma, o objetivo deste trabalho foi avaliar o efeito do gás ozônio na qualidade microbiológica do ar e das superfícies do interior de uma câmara frigorífica de armazenamento de queijo Minas Frescal.

\section{MATERIAL E MÉTODOS}

\section{Local e equipamento}

O experimento foi realizado no Laticínio da Fazenda da Aeronáutica de Pirassununga, avaliando-se a qualidade microbiológica da câmara fria destinada ao armazenamento de queijos minas frescal. A câmara constituída de painéis de poliestireno possui uma área total de $27,6 \mathrm{~m}^{2}$ (com medidas de 4,0 x 3,0 x 2,3 metros) mantida a temperatura de $5^{\circ} \mathrm{C}$.

A qualidade microbiológica foi avaliada por 60 dias sem aplicação de ozônio (sistema controle) e posteriormente por 60 dias com aplicação de ozônio na câmara. O equipamento utilizado para geração do ozônio no ar ambiente foi um ozonizador de ar da marca Interozone, modelo UEC $125^{\circledR}$, o qual fornece uma concentração final de ozônio de $0,03 \mathrm{mg} . \mathrm{L}^{-1} \mathrm{de}$ ar. O equipamento permaneceu ligado durante os 60 dias de experimento.

\section{Técnica de sedimentação}

A qualidade do ar interno da câmara fria foi verificada pela quantificação de microrganismos aeróbios mesófilos e bolores e fungos filamentosos, utilizando-se a técnica de sedimentação em placas. O método consistiu na exposição, por 15 minutos, de oito placas de Petri estéreis descartáveis de
$65 \mathrm{~cm}^{2}$ de área, sendo quatro placas contendo Ágar Plate Count PCA (DIFCO ${ }^{\circledR}$, USA) e as outras quatro contendo Ágar Batata Acidificado BDA (DIFCO ${ }^{\circledR}$, USA). As placas foram estrategicamente distribuídas duas a duas em quatro pontos da câmara fria a uma altura de 1,5 metros do chão, propiciando um contato direto do ar ambiente com a superfície do ágar contido nas placas. Esses pontos de amostragem foram pré-definidos a partir da observação da movimentação dos operadores do estabelecimento no interior da câmara durante suas rotinas de trabalho, que não foram alteradas para a realização do experimento. Os pontos amostrados foram: ao lado da porta de entrada, no fundo, do lado direito e do lado esquerdo da câmara.

As coletas foram realizadas durante 120 dias na câmara, sendo que nos primeiros 60 dias sem aplicação de ozônio e nos 60 dias subsequentes com o equipamento de ozônio ligado, gerando 0,03 mg de ozônio por litro de ar.

Após a coleta, as placas de PCA foram incubadas em estufa a $35^{\circ} \mathrm{C}$ por 48 horas para avaliação de aeróbios mesófilos, e as placas com BDA foram incubadas em estufa a $25^{\circ} \mathrm{C}$ por 72 horas para avaliação de bolores e fungos filamentosos (APHA, 1992).

Para determinação dos resultados finais foram realizados cálculos, considerando-se a contagem do número de colônias, a área de $65,0 \mathrm{~cm}^{2}$ das placas de Petri, o total de 1.440 minutos de um dia, e o tempo de 15 minutos de exposição de cada placa de acordo com a equação 1. O resultado final foi expresso em UFC. $\mathrm{cm}^{-2} \cdot \mathrm{dia}^{-1}$.

Equação 1:

Total de UFC $=\left(\mathrm{N}^{\circ}\right.$ de colônias/65 $) \times 1440$ 15

\section{Amostragem das superfícies da câmara}

Para a amostragem das superfícies da câmara foram utilizados swabs estéreis e 
descartáveis. As superfícies amostradas foram realizadas em cinco pontos de avaliação: porta, paredes (direita, esquerda e fundo da câmara) e estante da câmara fria.

As amostras foram coletadas em duplicata com auxílio de moldes metálicos estéreis determinantes da área de $10 \mathrm{~cm}^{2} \mathrm{de}$ esfregaço. As coletas foram realizadas a cada dois dias durante 60 dias com a câmara sem ozônio e a cada dois dias durante 60 dias com o ozonizador gerando $0,03 \mathrm{mg}$ de ozônio por litro de ar.

Após a coleta dos swabs, os mesmos foram colocados em tubos de ensaio contendo $9 \mathrm{~mL}$ de solução salina peptonada $0,1 \%$ e agitados vigorosamente. Posteriormente, foi realizada a contagem de microrganismos aeróbios em triplicata, expressa em UFC. $\mathrm{cm}^{-2}$ (APHA, 1992).

\section{Análise estatística}

Foi realizado para a sedimentação em placas um delineamento experimental casualizado com dois tratamentos (com a aplicação de ozônio e sem a aplicação de ozônio), no qual foram coletadas quatro placas para cada grupo microbiano em quatro pontos de avaliação na câmara fria durante o período de 120 dias em três repetições, totalizando 1440 placas para cada grupo microbiano. Para análise do efeito de tratamento utilizou-se o Teste $\mathrm{F}$ e para análise de efeito de tempo foi realizada estudo dos dias através de regressão pelo comando CONTRAST, ao nível de significância de 5\%.

Para a amostragem das superfícies de paredes e estantes da câmara pelos swabs foi realizado um delineamento experimental casualizado com dois tratamentos (antes da aplicação de ozônio e depois), com coleta de swabs em duplicata em cinco pontos de avaliação (direita, esquerda, estante, fundo e porta) na câmara fria a cada dois dias durante o período de 120 dias, totalizando 600 coletas de $s w a b$. Para análise do efeito de tratamento utilizou-se o Teste F e para análise de efeito local de realização do $s w a b$ foram realizados testes de comparação de médias, através do comando LSMEANS, utilizando-se o teste de Tukey - Kramer, ao nível de significância de $5 \%$. Os resultados foram analisados por meio do procedimento MIXED e medidas repetidas no tempo do programa SAS (SAS, 2004).

\section{RESULTADOS E DISCUSSÃO}

Os resultados das contagens de micror-

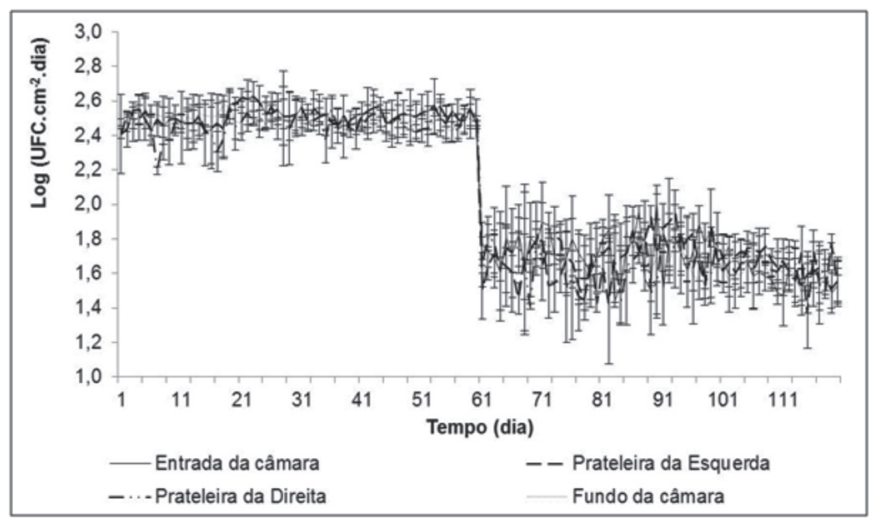

Figura 1 - Representação gráfica das populações de microrganismos aeróbios mesófilos sem e com aplicação do gás ozônio em câmara fria 
ganismos aeróbios mesófilos no ar da câmara em todos os pontos de amostragem antes e após a utilização do gás ozônio estão demonstrados na Figura 1.

A contagem inicial de microrganismos aeróbios mesófilos no ar da câmara foi bastante homogênea, variando entre $3,15 \times 10^{2}$ a 5,02 x $10^{2}$ UFC. $\mathrm{cm}^{-2} \cdot \mathrm{dia}^{-1}$, com contagem média de $3,19 \times 10^{2} \mathrm{UFC} \cdot \mathrm{cm}^{-2} \cdot \mathrm{dia}^{-1}$. Após a aplicação do ozônio, as contagens ficaram entre 4,87 x $10^{1}$ a 5,12 x $10^{2}$ UFC. $\mathrm{cm}^{-2} \cdot \mathrm{dia}^{-1}$, com média de 4,97 x 10 UFC.cm ${ }^{-2} \cdot \mathrm{dia}^{-1}$. Foi observada uma redução da contagem de aeróbios mesófilos de 0,81 ciclos, avaliada como estatisticamente significativa $(\mathrm{p}<0,05)$. Resultados de redução microbiológica similares foram observados por Chiattone (2006) em carne bovina maturada.

Adicionalmente, os resultados não indicaram diferenças significativas entre os pontos de amostragem e entre os diferentes dias de avaliação, o que indica que a contaminação no interior da câmara se manteve constante durante todos os dias dos ensaios. Além disso, o baixo nível de contaminação indica a boa qualidade do processo de higienização da câmara.

A partir da Figura 2 observa-se, graficamente, o comportamento das populações de bolores e fungos filamentosos, nos diversos pontos amostrados, durante o período de 60 dias com a câmara sem o tratamento e dos próximos 60 dias com o equipamento de ozônio em funcionamento.

A contagem inicial média de bolores e fungos filamentosos no ar da câmara foi de $1,24 \times 10^{2}$ UFC.cm² dia $^{-1}$. Após a aplicação do ozônio, a contagem média foi de 1,20 x 10 UFC.cm ${ }^{-2} \cdot$ dia $^{-1}$, sendo, portanto, observada uma redução média da contagem de bolores e fungos filamentosos de 1,01 ciclos, avaliada como estatisticamente significativa $(\mathrm{p}<0,05)$. Resultados obtidos para amoras estocadas em câmara com ozônio também indicaram bons efeitos do sanitizante, com supressão do crescimento fúngico por 12 dias (Barth et al., 1995).

A avaliação dos resultados mostrou que, novamente, não houve diferença entre os dias amostrados e pontos de coletas da câmara, indicando uma homogeneidade na contaminação da câmara e uma boa distribuição do ozônio nos pontos amostrados.

A Figura 3 apresenta as contagens de microrganismos aeróbios mesófilos nas superfícies das paredes, porta e estantes da câmara de estocagem e a Tabela 1 mostra as médias das contagens obtidas nos diferentes pontos de amostragem, antes e após a ozonização.

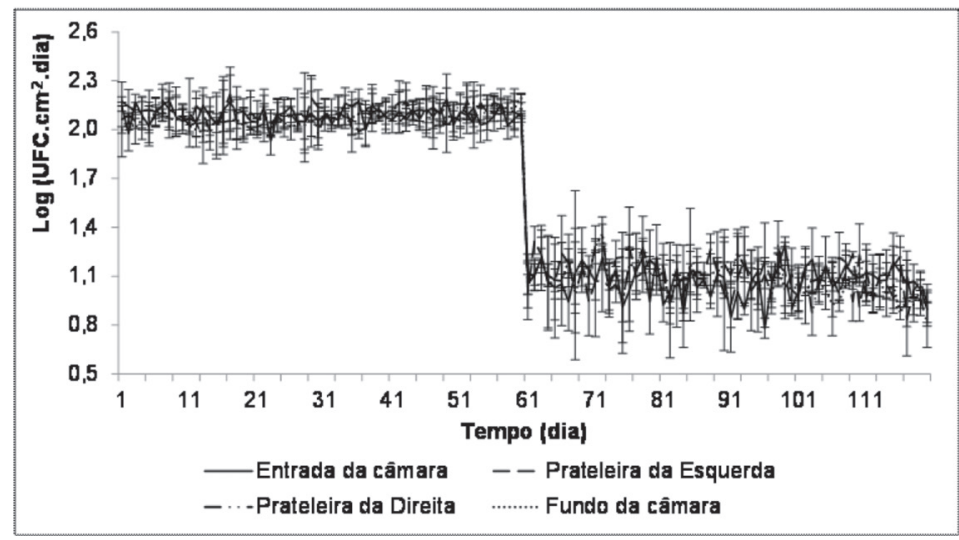

Figura 2 - Representação gráfica das populações de bolores e fungos filamentosos sem e com aplicação do gás ozônio em câmara fria 
Assim, observa-se, a partir dos dados da Tabela 1, que a contagem inicial de microrganismos aeróbios mesófilos nas superfícies da câmara foi pequena (máxima contagem $=16,6$ UFC. $\mathrm{cm}^{-2}$ ) e sem diferença significativa entre os pontos de coleta. Endres et al. (2010) verificaram resultados semelhantes aos deste estudo ao avaliarem o ar ambiente de câmaras frias de maturação de queijo ralado. Os autores observaram contagens de bolores e fungos filamentosos de 4,3 UFC.placa-1 (quando as superfícies $^{-1}$ internas da câmara foram amostradas com swabs) e de 9,1 UFC/100L ar, quando utilizaram um coletor de ar para enumerar populações de bolores e fungos filamentosos. Estas baixas contagens observadas em ambos estudos podem ser atribuídas ao bom estado de conservação das câmaras e à adequada higienização das mesmas.

A aplicação de ozônio determinou pequenas reduções nas contagens $(<0,5$ ciclo logarítmico), mas que, ainda assim, foram estatisticamente significativas $(\mathrm{p}<0,05)$ para

Tabela 1 - Médias (Log UFC.cm²) das contagens de microrganismos aeróbios mesófilos presentes nas superfícies da câmara frigorífica de queijo Minas frescal sem e com a utilização de ozônio como sanitizante

\begin{tabular}{lllllc}
\hline \multicolumn{5}{c}{ Pontos de coleta } \\
\hline & $\begin{array}{l}\text { Lado direito } \\
(\mathrm{Log}) \\
\text { UFC.cm }\end{array}$ & $\begin{array}{l}\text { Lado esquerdo } \\
(\mathrm{Log}) \\
\text { UFC.cm }\end{array}$ & $\begin{array}{l}\text { Estante } \\
(\mathrm{Log}) \\
\text { UFC.cm }\end{array}$ & $\begin{array}{l}\text { Fundo } \\
(\mathrm{Log}) \\
\text { UFC.cm }\end{array}$ & $\begin{array}{l}\text { Porta } \\
(\mathrm{Log} \\
\text { UFC.cm }\end{array}$ \\
\hline $\begin{array}{l}\text { Antes da sanitização } \\
\text { com ozônio }\end{array}$ & $1,18^{\mathrm{aA}}$ & $1,17^{\mathrm{aA}}$ & $1,22^{\mathrm{aA}}$ & $1,17^{\mathrm{aA}}$ & $1,17^{\mathrm{aA}}$ \\
$\begin{array}{l}\text { Depois da sanitização } \\
\text { com ozônio }\end{array}$ & $0,75^{\mathrm{cB}}$ & $0,77^{\mathrm{bcB}}$ & $1,14^{\mathrm{aA}}$ & $0,73^{\mathrm{cB}}$ & $0,90^{\mathrm{bB}}$ \\
Reduções & 0,43 & 0,40 & 0,08 & 0,40 & 0,27 \\
\hline
\end{tabular}

Letras minúsculas iguais na mesma linha são estatisticamente iguais pelo Tukey - Kramer $(\mathrm{p}>0,05)$ Letras maiúsculas iguais na mesma coluna são estatisticamente iguais pelo Teste $\mathrm{F}(\mathrm{p}>0,05)$.

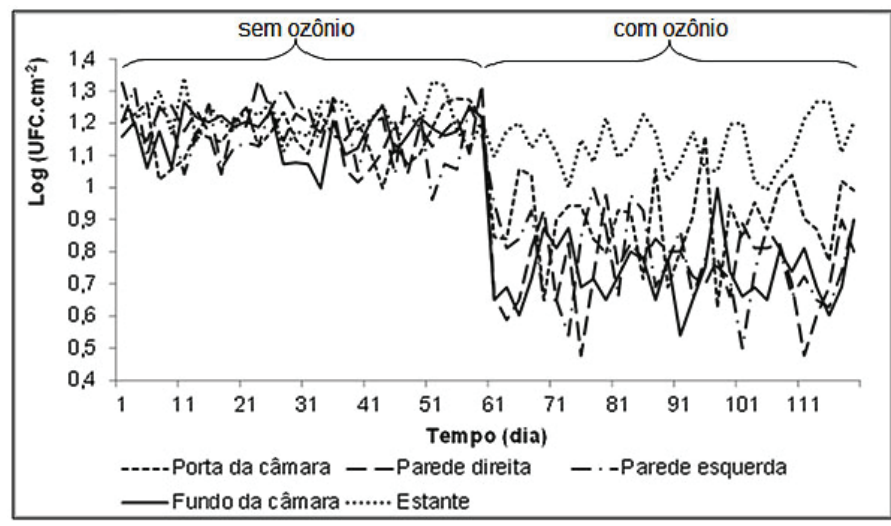

Figura 3 - Representação gráfica das populações de microrganismos aeróbios mesófilos sem e com aplicação do gás ozônio em superfícies de câmara fria 
todas às amostras, com exceção daquela coletada da estante $(\mathrm{p}>0,05)$. É possível que na presença de baixas contagens iniciais de microrganismos mesófilos aeróbios no interior da câmara o processo de ozonização não é muito efetivo, resultando em menores níveis de inativação do que aqueles que seriam observados em um ambiente mais contaminado.

\section{CONCLUSÕES}

A utilização do gás ozônio na concentração de $0,03 \mathrm{mg} . \mathrm{L}^{-1}$ em câmaras frias de armazenamento de queijo Minas Frescal possibilita uma melhor qualidade do ar de circulação e das superfícies das instalações, em virtude de uma redução média e constante de, respectivamente, 0,81 e 1,01 ciclos logarítmicos na contagem de microrganismos aeróbios mesófilos e bolores e fungos filamentosos.

A aplicação de ozônio mostra-se um método promissor para melhorar qualidade do ar e das superfícies interna de câmaras frias de laticínios, pela sua eficiência em baixas concentrações, por um curto período de tempo e decomposição em produtos não tóxicos. Além disso, uma vez obtido o equipamento, a geração do ozônio é de baixo custo, quando comparado com a compra periódica requerida para os demais sanitizantes.

\section{AGRADECIMENTOS}

Os autores agradecem à Fazenda da Aeronáutica pela possibilidade de utilização das instalações do laticínio e pelo apoio com mão de obra qualificada para a realização desta pesquisa.

\section{REFERÊNCIAS}

A MERICAN PUBLIC HEALTH ASSOCIATION (APHA). Standard methods for the examination of water and wastewater. 18. ed. Washington, 1992.

BARTH, M. M. et al. Ozone storage effects on anthocyanin content and fungal growth in blackberries. Journal of Food Science, v. 60, n. 6, p. 1286-1288, 1995.

BRASIL. Ministério da Agricultura, Pecuária e Abastecimento. Resolução $n^{\circ} 145$ de 13 de dezembro de 1996. Regulamento técnico MERCOSUL de identidade e qualidade de queijo Minas Frescal. Diário Oficial da República do Brasil, Brasília, 13 dez. 1996.

CHIATTONE, P. Ozônio e ácido ascórbico na coloração e microbiota da carne bovina maturada. 2006. 51f. Dissertação (Mestrado em Ciência e Tecnologia Agroindustrial) - Departamento de Ciência e Tecnologia Agroindustrial, Universidade Federal de Pelotas, Pelotas, 2006.

DHILlON, B. et al. Development and evaluation of an ozonated water system for antimicrobial treatment of durum wheat. Journal of Food Science, v. 74, n. 7, p. E396-E403, 2009.

ENDRES, J. C. T. et al. Avaliação da contaminação em indústria processadora de queijo ralado: estudo de caso. In: SIMPOSIO DE SEGURANÇA ALIMENTAR, 3., 2010, Florianópolis. Anais... Florianópolis: SBCTA, 2010. 1 CD-ROM.

MARTARELLO, V. D. Balanço hídrico e consumo de água de laranjeiras. In: CONGRESSO INTERINSTITUCIONAL DE INICIAÇÃO CIENTÍFICA, 5., 2011, Campinas. Anais... Campinas: IAC; ITAL, 2011.

GUZEL-SEYDIM, Z. B. et al. Use of ozone in the food industry. Lebensm.-Wiss, u.Technology, v. 37, n. 4, p. 453-460, 2004. 
KHADRE, M. A., YOUSEF, A. E. Decontamination of a multilaminated aseptic food packaging material and stainless steel by ozone. Journal of Food Safety, v. 21, n. 1, p. 1-13, 2001.

KHADRE, M. A. et al. Microbiological aspects of ozone applications in food: a review. Journal of Food Science. v. 66, n. 9, p. 1242-1252, 2001.

KIM, J. G. et al. Use of ozone to inactivate microorganisms on Lettuce. Journal of Food Safety, v. 19, n. 1, p. 17-37, 1999.

OLIVEIRA, C. J. B. et al. Risk factors associated with selected indicators of milk quality in semiarid northeastern Brazil. Journal of Dairy Science, v. 94, n. 6, 31663175, 2011.

OTHMANE, M.B. et al. Predicting cleaning time of ventilation duct systems in the food industry. Journal of Food Engineering, v. 105, n. 3, p. 400-407, 2011.

SALVADOR, A. et al. Effect of ozone on postharvest quality of persinomon. Journal of Food Science, v. 71, n. 6, p. 443-446, 2006.

SAS INSTITUTE. SAS user's guide:statictics. Version 9.1 Carey: SAS Institute, 2004. 1 CD-ROM.

TIWARI, B. K. et al. Kinetics of freshly squeezed orange juice quality changes during ozone processing. Journal of Agricultural and Food Chemistry, v. 56, n. 15, p. 64166422, 2008.

TIWARI, B. K. et al. Application of ozone in grain processing. Journal of Cereal Science, v. 51, n. 3, p. 248-255, 2010.

VEIGA, S. M. O. M. Utilização de água potável, hiperclorada e ozonizada e do ultra-som, combinados ou não, em um protótipo de chiller, para a sanificação de carcaças de frango. Sanificação de carcaças de frango: processos alternativos. 2003. 143f. Tese (Doutorado em Ciência dos Alimentos) - Universidade Federal de Lavras, Lavras, 2003. 